\title{
Embrittlement Prediction of Aged Austenitic Stainless Steel Welded Components Using Hardness Measurements
}

\author{
M. Shafy \\ Quality Assurance Department, National Center for Nuclear Safety and \\ Radiation Control, Atomic Energy Authority, Egypt.
}

\begin{abstract}
Embrittlement prediction of aged austenitic stainless steel welded components from hardness measurements as a nondestructive testing method was studied. Samples were thermally aged for 500, 1000, 2000, 3000, 4000 and 5000 hrs and the hardness profile was drawn through the base metal, heat affected as well as welds metal zones. The hardness increased with increasing the aging time up to $500 \mathrm{hrs}$ in the three considered zones, then it decreased at $1000 \mathrm{hrs}$ to the same value for both base and weld metal zones, while the heat affected zones exhibited more softening after 1000 hrs aging. Under further aging, the whole zones of weld joints became harder after $2000 \mathrm{hrs,} \mathrm{and} \mathrm{then}$ the hardness decreased with increasing aging time till 5000 hrs to the same order of the as-weld values. The degree of embrittlement prediction could be estimated by the change of hardness through different weld joint zones.
\end{abstract}

\section{Introduction:}

Austenitic stainless steels have been widely used in conventional and nuclear power plants for different applications such as superheaters and heater components. The wrought steels have good ductility and toughness over a wide range of temperatures and exhibit excellent corrosion and oxidation resistance. In any such installation, welded joints are critical load-bearing components and it is important that their properties did not deteriorate during post-weld heat treatment or at service temperatures. AISI type 316 steel is generally welded with either a consumable of approximately matching composition to the base material $19 \mathrm{Cr}-12 \mathrm{Ni}-2 \mathrm{Mo}$. The embrittlement behaviour that has been observed in stainless steels weld metal and led to a significant amount of research into these steels also takes place in welded material [1-5]. The aim of present work is to estimate the degree of embrittlement in weld joint by measuring the 
change of hardness (as non-destructive testing method) caused by different thermal aging condition.

\section{Experimental Work:}

\subsection{Materials:}

A plate of austenitic stainless steel type AISI 316 and a commercial rutile coated shielded arc electrodes, (class AWS (American Welding Society)) of type E316L with diameter $\phi=4 \mathrm{~mm}$, are used. The chemical composition of the used plate and electrode E316L is shown in Table (1).

Table (1): Chemical composition of the used plate of austenitic stainless steel type AISI 316 and electrode of type 316L

\begin{tabular}{|c|c|c|c|c|c|c|c|c|c|}
\hline & $\mathbf{C}$ & $\mathbf{C r}$ & $\mathbf{N i}$ & $\mathbf{M n}$ & $\mathbf{S i}$ & $\mathbf{P}$ & $\mathbf{S}$ & $\mathbf{M o}$ & $\mathbf{F e}$ \\
\hline Plate (wt\%) & 0.075 & 17.4 & 11.0 & 1.56 & 05 & 0.04 & 0.009 & 2.3 & Bal. \\
\hline $\begin{array}{c}\text { Electrode } \\
(\mathrm{wt} \%)\end{array}$ & 0.02 & 18.5 & 12 & 0.8 & 0.7 & - & - & 2.6 & Bal. \\
\hline
\end{tabular}

\subsection{Specimens Preparation}

Manual shielded metal arc welding (SMAW) process was used to prepare a weld joint. The welding parameters are as follows:

1. Plate of type AISI 316 with 12-mm thickness, Welding current: 55 Amp, and electrode type: AWS E 316L.

2. Root pass parameters: electrode diameter: nominal $2 \mathrm{~mm}$, positive electrode polarity and welding voltage: $60 \mathrm{~V}$.

3. Filling pass parameters: $4 \mathrm{~mm}$ electrode diameter, welding current: 120 Amp, DC, positive electrode polarity and welding voltage: $60 \mathrm{~V}$.

4. Position: flat

5. Joint type: single $\mathrm{V}$ joint with $60^{\circ}$

6. Root gap: $2 \mathrm{~mm}$

The two pieces to be welded are rigidly fixed with bolts at the edges in a fixture before welding process to reduce the wrapping of the welded joint after welding. 


\section{Experimental Technique:}

\subsection{X- Ray Radiography:}

All specimens are examined for soundness by radiographic testing after welding using X-Ray machine 200KVA.

\subsection{Heat Treatment:}

Weld specimens are aged at $400^{\circ} \mathrm{C}$ for various holding times ranging from 100 to $5000 \mathrm{hrs}$ followed by air-cooling. The heat treatment process is performed in a muffle furnace automatically controlled with accuracy of $\pm 5^{\circ} \mathrm{C}$. An additional $\mathrm{Ni}-\mathrm{Ni} / \mathrm{Cr}$ thermocouple attached to digital thermal indicator is used to check the temperature at the furnace from time to time.

\subsection{Hardness Test:}

Vickers micro-hardness testing machine is used to make at least tenhardness indentations on the studied weld deposit specimens in the as weld and after heat treatment conditions. Also, the test was carried out for the weld joint at the base metal; heat affected and welds metal zones. The applied load is $300 \mathrm{mg}$ and the indentation time is 30 according to ASTM E92-72. The arithmetic mean, the maximum and minimum values of the hardness number of each specimen are determined.

\section{Results and Discussions:}

Figures (4) show the micro-hardness profiles of the welded joints areas (weld metal, HAZ and base metal zones) in the as-welded condition and after various aging times of 100, 200, 500, 1000, 2000, 3000, 4000 and $5000 \mathrm{hrs}$ on the top surface of specimens. The average micro-hardness variation against the aging time is shown in Fig. (5).

For the as welded condition: the micro-hardness profile of the welded joint shows that the hardness variation through the weld metal zone is about 60 $\mathrm{HV}$, while the hardness variations of the HAZ and the base metal are about 21.8 $\mathrm{HV}$ and $20.5 \mathrm{HV}$, respectively. When the weld joint is subjected to aging, hardness variations within each zone of weld joint are observed, the maximum variation in the hardness values through the weld joint zones after aging for $2000 \mathrm{hrs}$ is shown in Fig.(3). For aging at $5000 \mathrm{hrs}$, the hardness variations through each weld zone become less as shown in Fig.(4). 


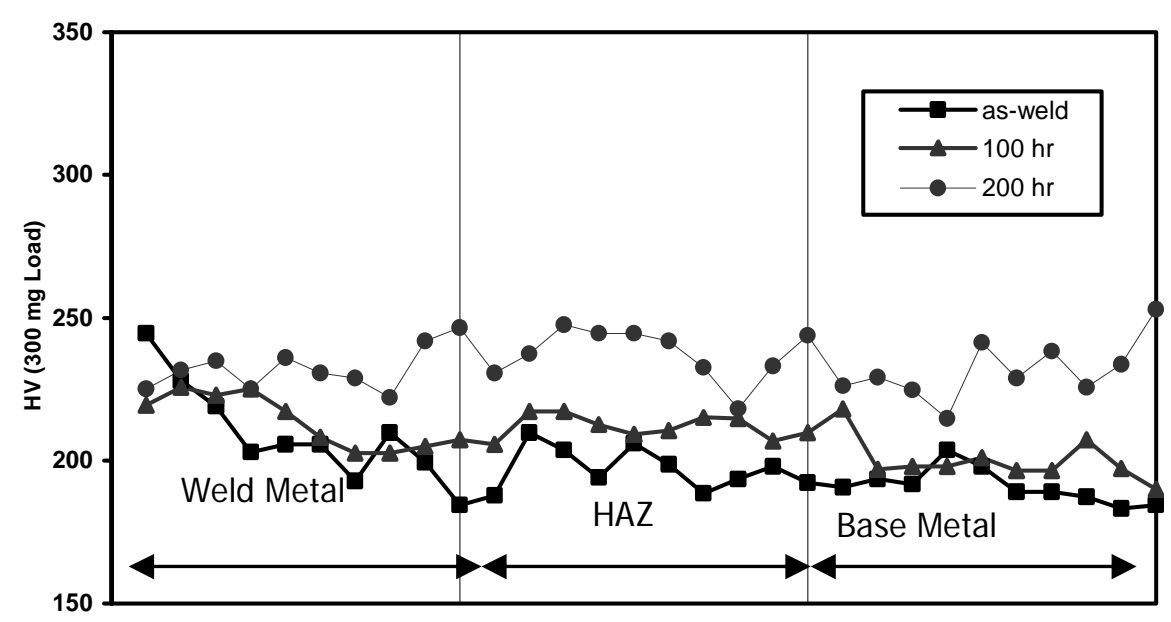

Measuring points

Fig. (1): Microhardness profiles of the weld joints of the as weld condition and after aging for $100 \mathrm{hrs}$ and for $200 \mathrm{hrs}$.

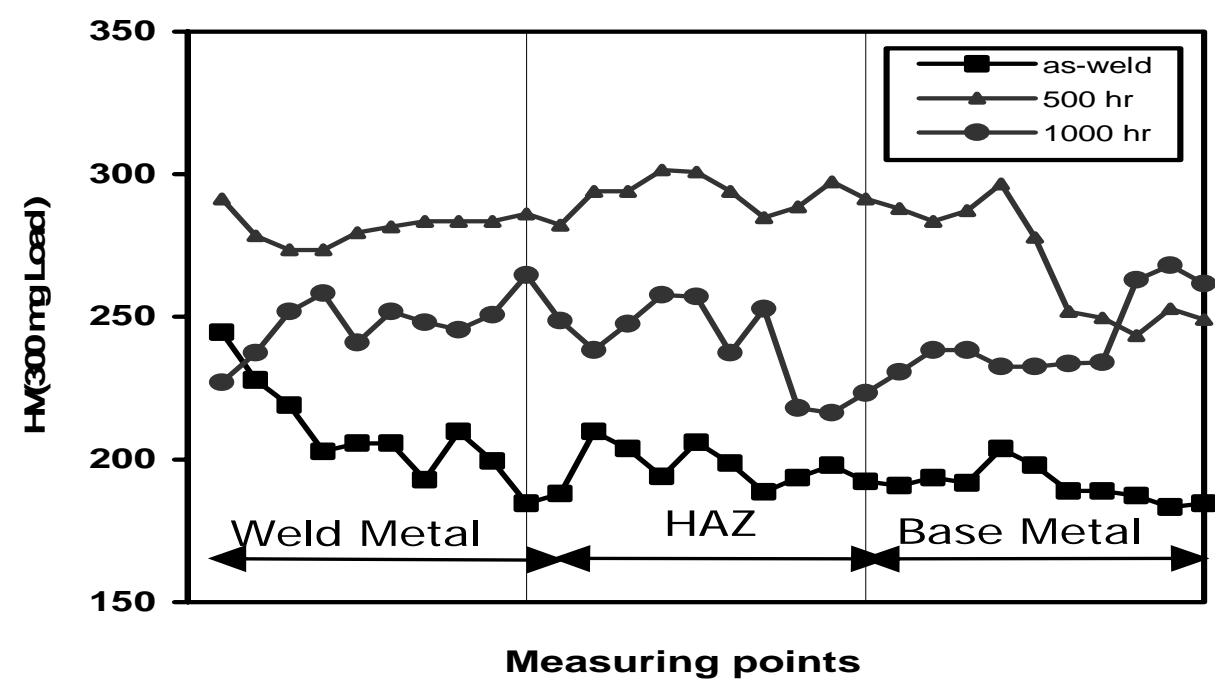

Fig. (2): Microhardness profiles of weld joints of the as weld condition and after aging for $500 \mathrm{hrs}$ and for $1000 \mathrm{hrs}$. 


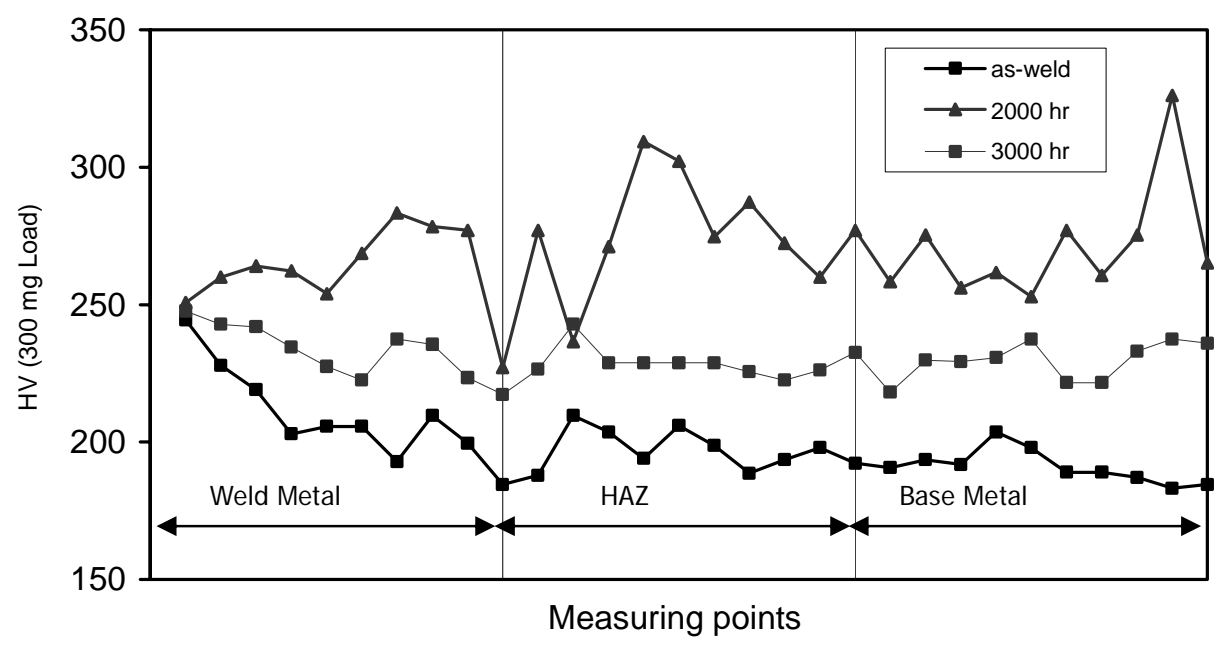

Fig. (3): Microhardness profiles of weld joints of the as weld condition and after aging for $2000 \mathrm{hrs}$ and for $3000 \mathrm{hrs}$.

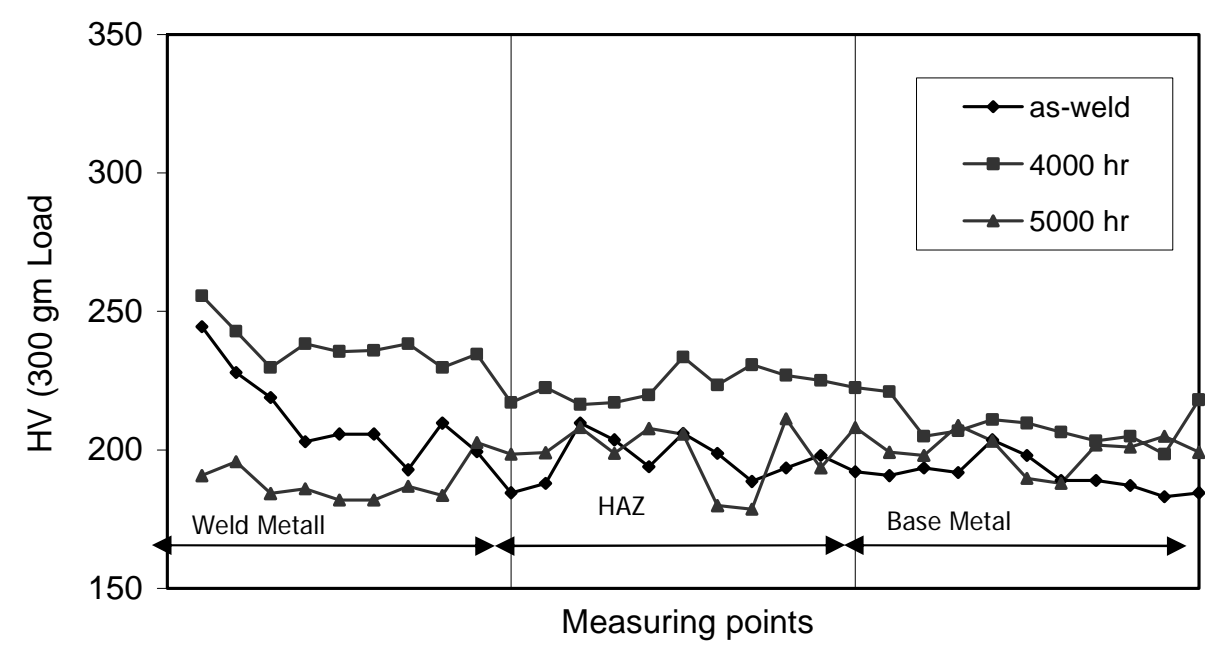

Fig. (4): Microhardness profiles of the as weld condition and after agingt for $4000 \mathrm{hrs}$ and for $5000 \mathrm{hrs}$.

It can be seen that the hardness increases with increasing the aging time to $500 \mathrm{hrs}$ in the three considered zones as shown Fig. (2). Then it decreases at $1000 \mathrm{hrs}$ to the same value for both base and weld metal zones, while the HAZ zones become softer at $1000 \mathrm{hrs}$ aging. For further aging, the whole zones of weld joint become harder at $2000 \mathrm{hrs}$ aging, then the hardness decreases with increasing aging time to $5000 \mathrm{hrs}$ to the same order of the as weld condition values. 
The initial decrease is suggested to be due to recovery processes. Thomas and Yapp [2] suggested that the weld metal may be softened in the initial stages of heat treatment due to recovery processes. Further heat treatment will lead to the formation of precipitates which cause increase in the hardness. For higher aging times, a balance occurs between recovery process and precipitation. Therefore the final result depends on any of them has higher rate.

The maximum average hardness value observed after $500 \mathrm{hrs}$ aging for the three weld zones, (WM, HAZ and BM) shows that the WM and HAZ zones have higher values than the base metal with $40 \%$ increase. This increase of hardness value at the weld metal could be attributed to the presence of $15 \%$ ferrite phase which contributes to the hardness value by $40 \%$. The increase of hardness value at HAZ could be attributed to the effect of thermal cycle on the microstructure variation. The increase of hardness at $500 \mathrm{hrs}$ aging can be attributed to the formation of coherent precipitates which increase the hardness.

Mathew et al. [3] reported that ABI, Tensile and Charpy impact tests carried out on CF-8 SS after aging at $473^{\circ} \mathrm{C}$ for 6,12 and 18 months revealed yield strength, tensile strength and micro-hardness increase with aging up to 12 months, while these values decreased on aging to 18 months and became equal to the strength and hardness of 6-months aged material.

Ishikawa and Yoshimura [4] showed that micro-hardness of ferrite phase in a low carbon molybdenum bearing CF-3M increased by $40 \%$ following aging at $473^{\circ} \mathrm{C}$ for $4000 \mathrm{hrs}$ and then decreased by $20 \%$ with further aging up to $10000 \mathrm{hrs}$ in consistence to the change in tensile properties. The hardness of the austenitic matrix did not vary due to aging. The variation behaviour of micro-hardness (BHN) with aging time in their investigation was similar to the variation in yield strength and tensile strength showing a peak in hardness after aging for 12 months and a fall in hardness after aging for 18 months equivalent to the hardness value of 6 months aged material, which is the same result reported by Mathew et al. [3].

Nichol et al. [5] studied the effect of exposure to 1000 hrs at 371, 482, and $593^{\circ} \mathrm{C}$ on the mechanical properties of four stainless steels. The evaluated properties were room temperature hardness, tensile properties and Charpy V-notch impact transition temperatures. Embrittlement at $482^{\circ} \mathrm{C}$ was characterized by an initial property change followed by a plateau region and then further property changed. The initial property change was attributed to the precipitation of interstitial compounds, although this was not supported by microstructure observations. The later property changes were attributed to $475^{\circ} \mathrm{C}$ embrittlement ( $\alpha$ precipitation). The early stages of embrittlement at 
$482^{\circ} \mathrm{C}$ of the 26 and $29 \% \mathrm{Cr}$ alloys are accompanied by wavelike contrast striations indicative to chromium atom clustering on $\{100\}$ planes. Upon embrittlement, the tensile deformation mode changes from turbulent slip to a more planar slip along $\{110\}$ matrix planes.

The impact energy against the aging time at different testing temperatures for 316L weld deposit was studied [6]. The results showed that the impact value decreased with increasing aging time. It significantly decreased after aging to $500 \mathrm{hrs}$ when tested at room temperature. At increasing the aging time, it slightly raised and then again decreased as tested at room temperature. Fig. (6) shows the results of impact energy against the aging time of weld metal deposit of type 316L tested at room temperature [6]. When comparing Fig. (6) to the present results of hardness variation, given in Fig. (5), it can be noted that at increasing the aging time to $500 \mathrm{hrs}$, the hardness and the impact energy values, which are taken as the degree of embrittlement of that weld deposit, are significantly increased. Also duplex stainless steel embrittlement under the effect of isothermal treatment at temperatures ranging from 400 to $500^{\circ} \mathrm{C}$ was investigated [7]. Charpy impact toughness was determined at room temperature using three specimens for each combination of aging time and temperature. The results showed that the toughness decreased with increasing the aging time. In the cases of aging at 450,475 and $500^{\circ} \mathrm{C}$, a significant decrease in toughness occurred in the initial stage. However, the drop in toughness in the same early stage was negligible in the case of aging at $400^{\circ} \mathrm{C}$. Impact energy of $10 \mathrm{ft}-\mathrm{lb}(13.5 \mathrm{~J})$ was usually considered as a valid criterion for the complete embrittlement condition. For specimens aged at $475^{\circ} \mathrm{C}$, it takes $32 \mathrm{hrs}$ to reach this condition; the results were consistent with those obtained from fractoraphic evaluations. It is evident that aging at $475^{\circ} \mathrm{C}$ leads to severe deterioration in the toughness of the investigated steel. The variation of Rockwell C hardness (HRC) as a function of aging time at different aging temperatures was measured. The hardness increased with increasing aging time at all temperatures except for the early stage of the aging at $400^{\circ} \mathrm{C}$, Fig. (6). This result indicated that the embrittlement phenomenon is due to an increase in hardness caused by age hardening of the ferrite phase.

It can be seen that the behaviour of hardness curves against aging time is more or less similar to that of impact curve against temperature. This can be observed when comparing the impact energy curves abstracted from other previous [6\&7] studies (Figs 6 and 7) to be the hardness test curves (Figs 5 and 8). Accordingly, the measurements of hardness and/or toughness can be a reasonable trend to predict the embrittlement in the weld joint zones. 


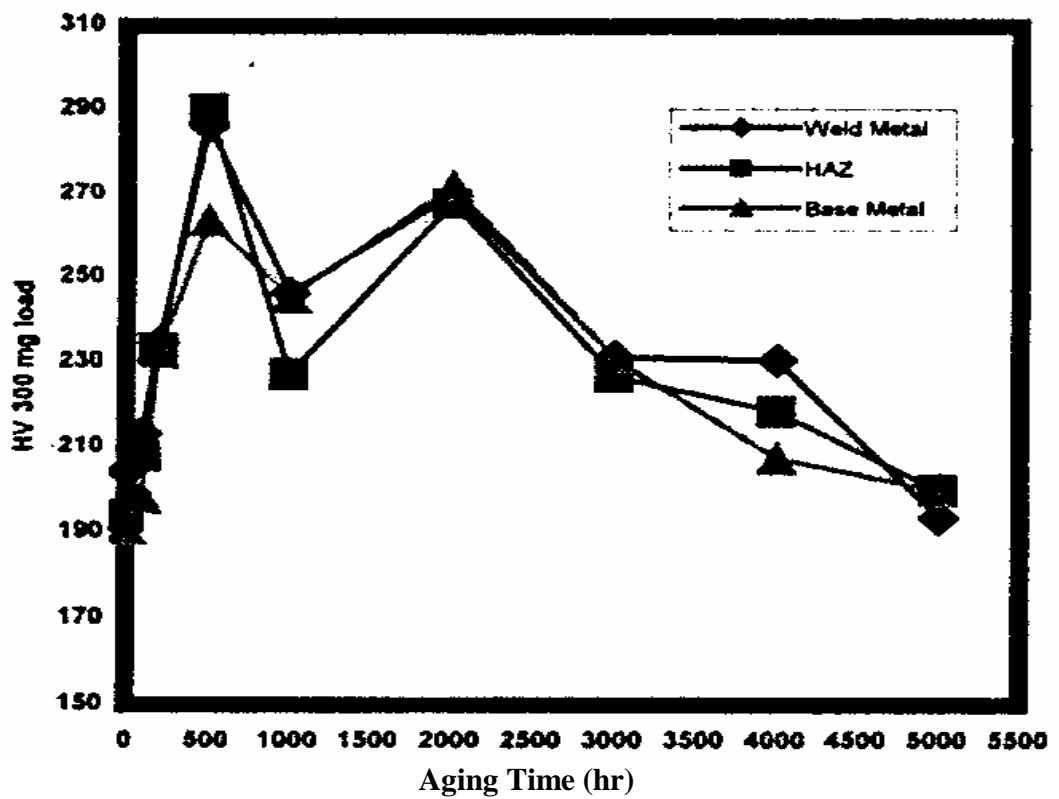

Fig. (5): Microhardness variation Average of aging of three zones.

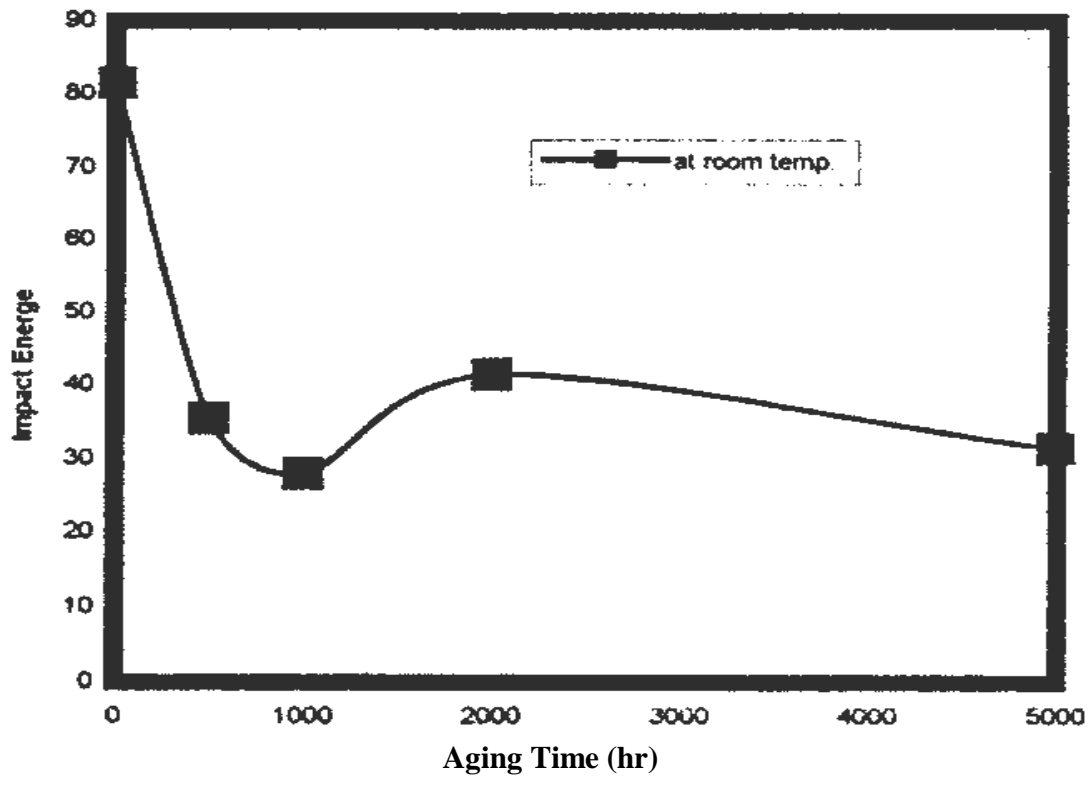

Fig. (6): Effect of aging on impact properties of $316 \mathrm{~L}$ weld metal aged at $400{ }^{\circ} \mathrm{C}$. 


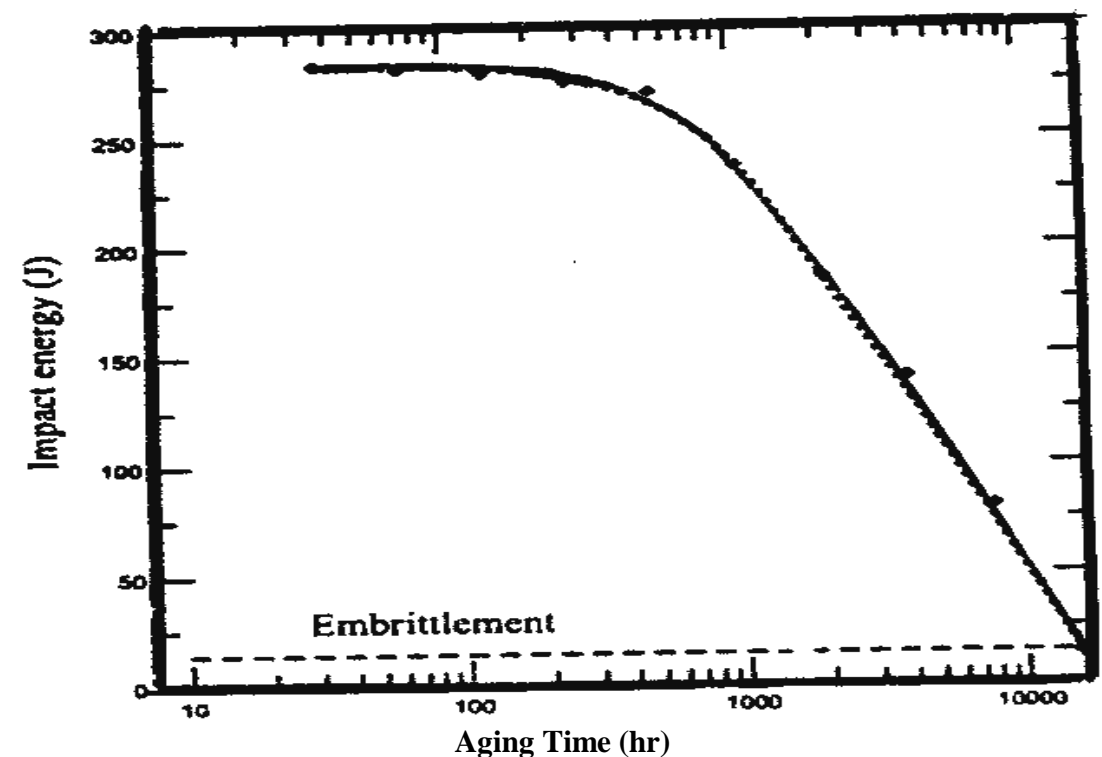

Fig. (7): Effect of aging on impact properties of 2205 duplex stainless steel aged at $400{ }^{\circ} \mathrm{C}$.

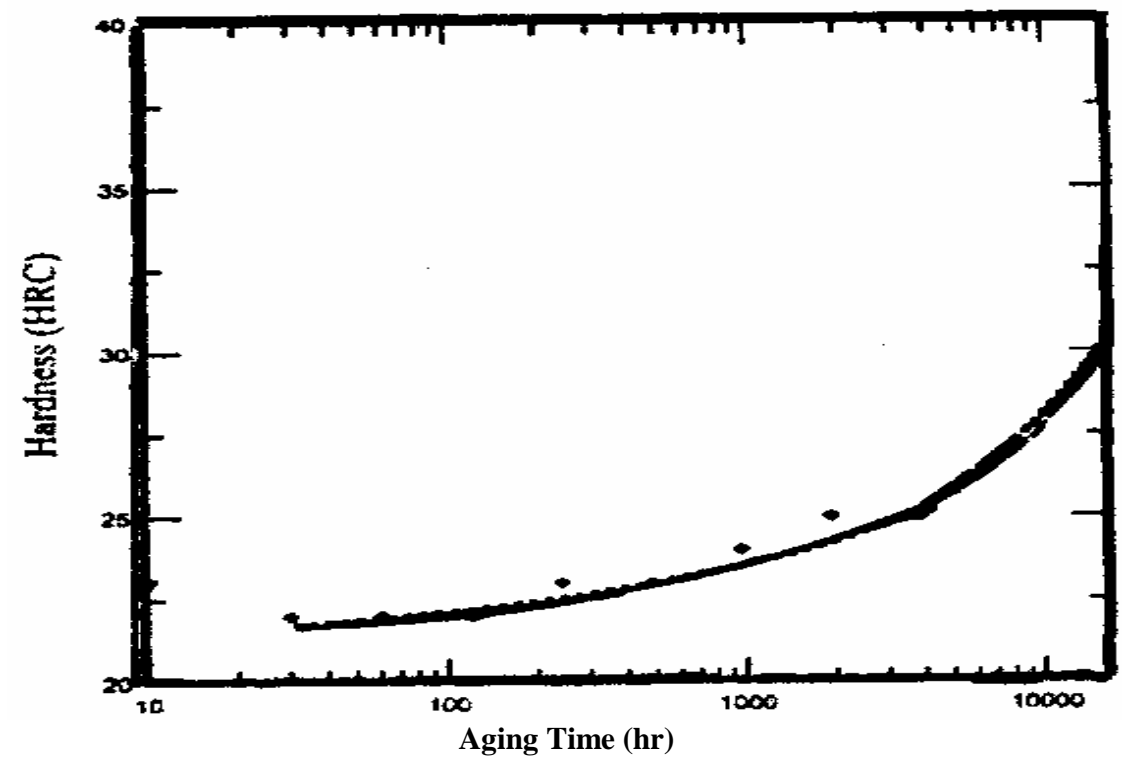

Fig. (8): Effect of aging on microhardness of 2205 duplex stainless steel aged at $400{ }^{\circ} \mathrm{C}$. 
On the basis of these relations, the field indentation microprobe is developed [8] to evaluate nondestructively -in situ- the structural integrity of welded components, affected zones, base materials for assessing the integrity of structures following accidents or severe service conditions, as well as evaluating internal or surface cracking which may occur due to embrittlement conditions [9-11].

\section{Conclusions:}

1. The hardness as nondestructive test can be used to predict the embrittlement of different weld joint zones. It gives good results compared to the impact result. Portable hardness tester as a nondestructive method is satisfactory for evaluation purposes of aged components.

2. The maximum variation in the hardness values is found at the weld joint zones after aging for $2000 \mathrm{hrs}$, and decreases for aging at $5000 \mathrm{hrs}$.

3. The max average hardness value is observed after $500 \mathrm{hrs}$ aging for the three weld zones, (WM, HAZ and BM). But the WM and HAZ show higher values than the base metal with $40 \%$ increase. The increase of hardness at $500 \mathrm{hrs}$ aging can be attributed to precipitate formation.

\section{Acknowledgment:}

The author would like to thank Prof. T. Khalifa for his advice and Eng. A.N. Kamel for his assistance during the course of this work.

\section{References:}

1. T. M. Angeliu, E. L. Hall, M. Larsen, A. Linsebigler, and C. Mukira; GE Research \& Development Center, 98CRD067, class 1, April (1998).

2. R. G. Thomas and D. Yapp; Welding Journal: 361s (1979).

3. M.D. Mathew, L. M. Lietzan, K. L. Murty, V. N. Shah; Material Science and Engineering A269, 186 (1999).

4. Y. Ishikawa, T. Yoshimura; Mater. Trans., JIM 35, 895 (1994).

5. T. J. Nichol, A. Datta, and G. Aggen; Metallurgical Transactions, 11A, 573 (1980).

6. M. A. Shafy and A. N. Kamel; Submitted to Egypt. J. Solids.

7. Kuang Liang Weng, Ting Hung Chen, and Jer Ren Yong; Bulletin of the College of Engineering, N.T.U., 89, 45 (2003).

8. F. M. Haggag, R. K. Nanstad, and D. N. Brarski; The American Society of Mechanical Engineering, PVP- Vol. 170, Book No. H00485, 101 (1989). 
9. ASME Boiler and pressure vessel code; Section V: Nondestructive Examination, The American Society of Mechanical Engineering, New York, N.Y.10017; Edition 2004.

10. C. V. Subramanian, M. Thavasimuthu, A. S. Ramesh, T. Jayakumar, P. Kalyanasundaram and Baldev Raj, $14^{\text {th }}$ World Conference on Nondestructive Testing, New Delhi, India, December 8-13 (1996).

11. ASME Boiler and Pressure Vessel Code; Section XI: In-Service Inspection, The American Society of Mechanical Engineering, New York, N.Y.10017; Edition 2004. 